The University of Maine

\title{
DigitalCommons@UMaine
}

Maine-Syracuse Longitudinal Papers

Maine-Syracuse Longitudinal Study

2008

\section{Homocysteine and cognitive performance: Modification by the ApoE genotype}

Merrill F. Elias

University of Maine, mfelias@maine.edu

Michael A. Robbins

University of Maine, michael.robbins@umit.maine.edu

Marc M. Budge

Australian National University

Penelope K. Elias

University of Maine

Gregory A. Dore

University of Maine

See next page for additional authors

Follow this and additional works at: https://digitalcommons.library.umaine.edu/

longitudinal_papers

\section{Repository Citation}

Elias, Merrill F.; Robbins, Michael A.; Budge, Marc M.; Elias, Penelope K.; Dore, Gregory A.; Brennan, Suzanne L.; Johnston, Carole; and Nagy, Suzsanna, "Homocysteine and cognitive performance: Modification by the ApoE genotype" (2008). Maine-Syracuse Longitudinal Papers. 48.

https://digitalcommons.library.umaine.edu/longitudinal_papers/48

This Article is brought to you for free and open access by DigitalCommons@UMaine. It has been accepted for inclusion in Maine-Syracuse Longitudinal Papers by an authorized administrator of DigitalCommons@UMaine. For more information, please contact

um.library.technical.services@maine.edu. 


\section{Authors}

Merrill F. Elias, Michael A. Robbins, Marc M. Budge, Penelope K. Elias, Gregory A. Dore, Suzanne L. Brennan, Carole Johnston, and Suzsanna Nagy 


\title{
Homocysteine and cognitive performance: Modification by the ApoE genotype
}

\author{
Merrill F. Elias ${ }^{\mathrm{a}, *}$, Michael A. Robbins ${ }^{\mathrm{a}}$, Marc M. Budge ${ }^{\mathrm{b}}$, Penelope K. Elias ${ }^{\mathrm{a}}$, \\ Gregory A. Dore ${ }^{\text {a }}$, Suzanne L. Brennan ${ }^{\text {a }}$, Carole Johnston ${ }^{c}$, Zsuzsanna Nagy ${ }^{\text {d }}$ \\ a Department of Psychology, University of Maine, Orono, ME 04469, USA \\ ${ }^{\mathrm{b}}$ Department of Geriatric Medicine, Australian National University, The Canberra Hospital, Woden, ACT 2605, Australia \\ c Oxford Project to Investigate Memory and Ageing (OPTIMA), Department of Physiology, \\ Anatomy \& Genetics, University of Oxford, Oxford OX1 3PT, UK \\ d Neuroscience Division, Medical School, University of Birmingham, Birmingham B15 2TT, UK \\ Received 11 July 2007; received in revised form 28 September 2007; accepted 18 October 2007
}

\begin{abstract}
We hypothesized that the magnitude of the association between plasma homocysteine concentration and cognitive performance is larger for ApoE- $\varepsilon 4$ carriers than for non-carriers. Nine hundred eleven dementia-free and stroke-free subjects (59\% women) from the Maine-Syracuse study (26-98 years old) were stratified into no-ApoE- $\varepsilon 4(n=667)$ and ApoE- $\varepsilon 4$ carrier $(n=244)$ cohorts. Employing a cross-sectional design and multiple regression analyses, plasma homocysteine was related to multiple domains of cognitive performance within these cohorts. When unadjusted, and with adjustment for age, education, gender, ethnicity, and previous cognitive examinations, homocysteine concentrations were inversely related to cognitive performance within both ApoE cohorts, with higher magnitude of associations within the ApoE- $\varepsilon 4$ cohort. With adjustment for cardiovascular disease risk factors, cardiovascular disease, and B-vitamin concentrations, the higher magnitude of associations between plasma homocysteine and cognitive performance within the ApoE- $\varepsilon 4$ cohort relative to the no-ApoE- $\varepsilon 4$ cohort persisted; but associations of plasma homocysteine and cognitive performance were attenuated and no longer significant within the no-ApoE- $\varepsilon 4$ cohort. Presence of the ApoE- $\varepsilon 4$ allele modifies the relation between plasma homocysteine and cognitive performance.
\end{abstract}

(C) 2007 Elsevier Ireland Ltd. All rights reserved.

Keywords: ApoE; Homocysteine; Cardiovascular risk factors; Vitamins; Cognitive performance

Elevated plasma homocysteine (tHcy) is a risk factor for cognitive deficit $[2,7,11,12,28,33,37,38,45]$, cognitive decline $[26,46]$, and dementia $[5,25,40]$. It has been hypothesized that tHcy is associated with lowered cognitive function via its positive association with other risk factors for cardiovascular disease (CVD) and CVD-related events [11,12,35]. Other possibilities are that vitamins involved in tHcy metabolism, folic acid, vitamin $B_{6}$ and vitamin $B_{12}$, [39] confound relations between tHcy and cognition [19] and/or tHcy itself has neurotoxic and excitotoxic properties [14,20,24,32].

ApoE is a lipoprotein involved in lipid transport and neuronal repair and synaptogenesis after injury [30]. The protein has three isoforms, ApoE- $\varepsilon 2$, ApoE- $\varepsilon 3$, and ApoE- $\varepsilon 4$. The ApoE- $\varepsilon 4$ genotype represents a genetic risk factor for Alzheimer's disease

\footnotetext{
* Corresponding author. Tel.: +1 207244 9674; fax: +1 2075816128

E-mail address: mfelias@aol.com (M.F. Elias).
}

$[13,36]$ and may also be a risk factor for lowered cognitive performance and cognitive decline in healthy individuals $[1,43]$. ApoE- $\varepsilon 4$ carriers are also more vulnerable to cognitive deficits related to risk factors such as low vitamin $\mathrm{B}_{12}$ blood concentrations [3,4], peripheral vascular disease and atherosclerosis [15]. Yet, despite the evidence that both higher levels of tHcy and the presence of the ApoE- $\varepsilon 4$ allele are related to poorer cognitive performance, few studies have tested the hypothesis that the ApoE- $\varepsilon 4$ genotype modifies relations between plasma tHcy and cognitive performance $[7,38]$.

In a community sample of persons 50-70 years old, the association of higher tHcy with poorer performance on the Rey Auditory Verbal Learning Test was stronger in persons homozygous for the ApoE- $\varepsilon 4$ allele as compared to all other participants [38]. However, another community sample study of persons 61-73 years old did not find that associations of tHcy with cognitive decline were moderated by the ApoE- $\varepsilon 4$ allele [7]. 
Given the inconsistencies in the few studies available, we tested the following hypotheses with respect to non-demented community-based adults: (1) compared to persons without the ApoE- $\varepsilon 4$ allele, the magnitude of the association between tHcy and cognitive performance is greater for ApoE- $\varepsilon 4$ allele carriers; (2) this modification of relations between tHcy and cognition by ApoE genotype is not limited to global cognitive performance but is evident for specific cognitive domains; and (3) this modification will be observed with adjustment for CVD events, CVD risk factors, and blood concentrations of B-vitamins (folate, vitamin $\mathrm{B}_{6}$, and vitamin $\mathrm{B}_{12}$ ).

The University of Maine approved this investigation. Informed consent for data collection was obtained from all participants in this community-based sample from the MaineSyracuse Longitudinal Study (MSLS), which began in 1975. Recruitment and data collection procedures for the MSLS have been described in detail [11]. This study is a cross-sectional analysis of data obtained at the sixth wave of MSLS testing (2001-2006), the first and only wave for which tHcy and ApoE data were obtained. Of the 965 participants, aged between 26 and 98 years, subjects were excluded in the following sequence: (1) no-ApoE genotype data obtained $(n=6)$; (2) dementia $(n=9)$; (3) stroke $(n=32)$, (4) active dialysis treatment $(n=5)$; (5) treatment for alcoholism $(n=1)$; (6) inability to read test material $(n=1)$. Stroke, defined as a focal neurological deficit of acute onset persisting more than $24 \mathrm{~h}$, was based on selfreport and record review (with permission), but confirmed by hospitalization, treatment, or both. The clinical diagnosis of dementia was determined from cognitive data, self-report, and medical records, using the National Institute of Neurological and Communicative Diseases and Stroke/Alzheimer's Disease and Related Disorders Association (NINCDS-ADRDA) criteria [27]. The characteristics of the final sample $(n=911)$ are presented in Table 1.

Participants completed the Center for Epidemiological Studies Depression Scale (CES-D [34]) within one week prior to neuropsychological testing. Following a fast from midnight, a blood sample was drawn and a light breakfast was served. A physical examination and neuropsychological testing followed.

Fasting blood samples were collected in standard ethylenediaminetetraacetic acid tubes for plasma tHcy and plasma $\mathrm{B}_{6}$ determinations and in serum separator (gel and clot activator) tubes for serum determinations. Plasma tHcy concentrations were assessed using a fluorescence polarization immunoassay, which has a coefficient of variation for tHcy assays of less than $3.5 \%$ [41]. Determination of plasma vitamin $\mathrm{B}_{6}$, high sensitivity C-reactive protein (hs-CRP), serum folate, serum vitamin $\mathrm{B}_{12}$, total cholesterol, triglycerides, glucose, and creatinine was performed as recently described [11]. Standard ApoE genotyping used polymerase chain reaction (PCR) and restriction enzyme digest with HhaI $[11,17]$.

We employed the Mini Mental State Examination (MMSE) and the Maine-Syracuse neuropsychological test battery [11], which included the Similarities test from the Wechsler Adult Intelligence Scale (WAIS) and four composite scores resulting from a previous factor analysis which identified four relatively independent cognitive domains: Visual-Spatial Memory and Organization, Scanning and Tracking, Verbal Episodic Memory and Working Memory. Each composite score was constructed by summing standard scores for multiple individual tests taken from the Halstead Reitan Neuropsychological Test Battery, the Wechsler Memory Scale-R, the original WAIS, and the WAIS III [23].

Test scores were transformed to $z$-scores. This linear transformation results in a mean of zero and a S.D. of 1.00 for each test and enables expression of regression coefficients for the cognitive measures in terms of S.D. units. Factor analytic methods and tests making up the composites are fully described in a recent paper [11] and in the online supplement (http://www.sciencedirect.com/science/journal/03043940).

These previously identified composites were confirmed via replication of the factor analysis. Similarities (abstract reasoning) scores loaded on multiple factors and were treated as a separate measure. In addition to composite scores based on factor analysis, a Global Composite score was calculated by averaging the $z$-scores for all individual tests (excluding the MMSE). The Global Composite and MMSE were considered separate measures of global performance.

A natural log transformation of the raw plasma tHcy values (ln-tHcy) was necessary in order to achieve a normal distribution. ApoE genotype was categorized as one or two $\varepsilon 4$ alleles (ApoE$\varepsilon 4$ cohort) versus no $\varepsilon 4$ alleles (no-ApoE- $\varepsilon 4$ cohort) given the small number with two $\varepsilon 4$ alleles $(n=30)$.

Covariates were organized into three sets. The Basic set included age (years), gender, education (years), number of exposures to neuropsychological tests prior to wave six, and race/ethnicity (non-Hispanic Caucasian or other). The CVD set included CVD event/s (yes/no), diabetes mellitus (yes/no), systolic blood pressure $(\mathrm{mmHg}, \mathrm{BP})$, presence of mild renal dysfunction (yes/no), total cholesterol $(\mathrm{mg} / \mathrm{dl})$, body mass index $\left(\mathrm{kg} / \mathrm{m}^{2}, \mathrm{BMI}\right)$, depressed mood (yes/no), hs-CRP, and selfreported number of cigarettes smoked (per week), alcohol consumption (cl/week), and coffee consumption (number of $24 \mathrm{cl}$ cups/day). Diabetes mellitus was defined as follows: treatment with insulin, oral antidiabetic agents, or fasting glucose level of $126 \mathrm{mg} / \mathrm{dl}$ or above. Mild renal dysfunction was defined as an estimated creatinine clearance using the Cockcroft-Gault formula [6] of less than $60 \mathrm{ml} / \mathrm{min}$ [22]. Using the Framingham Study criteria [9], the CVD event variable was defined by the presence of any of the following: myocardial infarction $(3.9 \%)$, coronary artery disease $(7.7 \%)$, congestive heart failure $(2.3 \%)$, angina pectoris $(5.3 \%)$, or transient ischemic attack $(3.7 \%)$. The B-vitamin set included blood concentrations of folate, vitamin $\mathrm{B}_{6}$ and vitamin $\mathrm{B}_{12}$. All of the covariates were related significantly to the independent variables, the dependent variables, or both.

The relation between $\ln$-tHcy and the measures of cognitive functioning was adjusted in a hierarchical progression of regression models using the sets of covariates as follows: (1) Unadjusted (no covariates); (2) the Basic set; (3) the Basic + CVD set; and (4) the Expanded set (Basic + CVD + Bvitamins). All variables within each model were entered simultaneously. 
Table 1

Demographic and health characteristics of the no-ApoE- $\varepsilon 4$ allele and the ApoE- $\varepsilon 4$ allele cohorts

\begin{tabular}{|c|c|c|c|c|c|c|}
\hline \multirow[t]{2}{*}{ Variable } & \multicolumn{3}{|c|}{ No-ApoE- $\varepsilon 4$ allele $(n=667)$} & \multicolumn{3}{|c|}{ ApoE- $\varepsilon 4$ allele $(n=244)$} \\
\hline & Mean & S.D. & $\%$ & Mean & S.D. & $\%$ \\
\hline Homocysteine $(\mu \mathrm{mol} / \mathrm{l})$ & 10.0 & 3.6 & & 9.8 & 3.2 & \\
\hline Age (years) & 62.6 & 12.9 & & 60.7 & 12.3 & \\
\hline Education (years) & 14.6 & 2.7 & & 14.6 & 2.8 & \\
\hline Folate (ng/dl) & 17.3 & 5.2 & & 16.8 & 5.2 & \\
\hline Vitamin $\mathrm{B}_{6}\left(\mathrm{PLP}^{\mathrm{a}}\right), \mathrm{nmol} / \mathrm{l}$ & 95.6 & 92.2 & & 87.9 & 86.5 & \\
\hline Vitamin $B_{12}(\mathrm{pg} / \mathrm{ml})$ & 533.7 & 288.1 & & 511.0 & 258.6 & \\
\hline C-reactive protein & 4.4 & 4.8 & & 3.3 & 3.6 & \\
\hline Systolic BP (mmHg) & 132.3 & 21.3 & & 129.6 & 22.2 & \\
\hline Diastolic BP (mmHg) & 71.1 & 10.1 & & 69.9 & 9.7 & \\
\hline Alcohol (cl/week) & 4.5 & 7.8 & & 4.8 & 10.1 & \\
\hline Cigarettes (week) & 8.2 & 34.5 & & 12.8 & 43.2 & \\
\hline Total cholesterol (mg/dl) & 202.3 & 40.0 & & 201.6 & 39.3 & \\
\hline Body mass index $\left(\mathrm{kg} / \mathrm{m}^{2}\right)$ & 29.5 & 5.9 & & 29.4 & 6.4 & \\
\hline Coffee (cups/day) & 1.8 & 1.9 & & 1.8 & 1.9 & \\
\hline Gender (female) & & & 58.5 & & & 60.7 \\
\hline Ethnicity (caucasian) & & & 91.6 & & & 87.3 \\
\hline Diabetes mellitus & & & 12.4 & & & 13.9 \\
\hline Obesity $\left(\mathrm{BMI} \geq 29.9 \mathrm{~kg} / \mathrm{m}^{2}\right)$ & & & 40.5 & & & 41.0 \\
\hline CVD event & & & 15.1 & & & 14.8 \\
\hline Mild renal dysfunction & & & 17.1 & & & 16.0 \\
\hline Depressed mood ${ }^{\mathrm{b}}$ & & & 10.2 & & & 10.7 \\
\hline Folate deficit ${ }^{\mathrm{c}}$ & & & 0.0 & & & 0.0 \\
\hline Vitamin $_{6}$ deficit $^{\mathrm{d}}$ & & & 14.6 & & & 14.8 \\
\hline Vitamin $\mathrm{B}_{12}$ deficit $^{\mathrm{e}}$ & & & 3.5 & & & 4.1 \\
\hline Quintile 5 homocysteine $\mathrm{f}^{\mathrm{f}}$ & & & 19.8 & & & 20.1 \\
\hline
\end{tabular}

a Pyridoxal 5' -phosphate.

b CES-depression scores $>16$.

c Folate deficiency defined as value $<3 \mathrm{ng} / \mathrm{ml}$.

d Vitamin $\mathrm{B}_{6}$ deficiency defined as value $<30 \mathrm{nmol} / \mathrm{l}$.

e Vitamin $B_{12}$ deficiency defined as value $<200 \mathrm{pg} / \mathrm{ml}$.

f Homocysteine values $\geq 11.8 \mu \mathrm{mol} / 1$.

Residual plots and absence of significant quadratic trends ( $p$ s $>.20$ ) confirmed the appropriateness of the straight-line fit for tHcy. For each model, tests of interactions of the independent variables with age and gender were statistically non-significant ( $p$ s > .10).

The number of persons classified into the possible ApoE genotypes was as follows: $2 / 2(n=17), 2 / 3(n=103), 2 / 4$ $(n=21), 3 / 3(n=547), 3 / 4(n=193)$, and $4 / 4(n=30)$. The ApoE$\varepsilon 4$ cohort $(2 / 4,3 / 4,4 / 4)$ represented $26.6 \%$ of our sample. This representation is within the range $(24-30 \%)$ reported in other studies of ApoE [3,15,38].

The ApoE- $\varepsilon 4$ cohort was younger $(t=2.00, p<.05)$, had lower hs-CRP values $(t=3.51, p<.001)$ than the no-ApoE- $\varepsilon 4$ cohort and had a modestly higher proportion $\left(\chi^{2}=3.84, p<.05\right)$ of minority persons (Table 1). No differences between ApoE cohorts were observed for mean tHcy or B-vitamin concentrations, low vitamin or high tHcy status, or other demographic or health variables $(p$ range $=.09-.95)$.

With main effects in the model, statistically significant ApoE by tHcy interactions $(p<.05)$ were observed for the Unadjusted model and for one or more adjusted models for the Global composite, the MMSE, Working Memory, and Similarities. Thus in a second step with respect to evaluating effect modification of tHcy by ApoE, $t$-tests of the differences between regression coef- ficients obtained for the two ApoE- $\varepsilon 4$ cohorts were performed for these variables. Table 2 shows the regression coefficients for each ApoE group for the Global composite, the MMSE, Working Memory, and Similarities. It may be seen that regression coefficients were consistently higher for the ApoE- $\varepsilon 4$ cohort than for the no-ApoE- $\varepsilon 4$ cohort. Significant differences (Table 2) between regression coefficients were obtained for each of the four variables. However, for the Global composite and Similarities, differences between the regression coefficients did not achieve statistical significance with adjustment for the Basic and the Basic + CVD covariate sets, respectively.

For the Unadjusted model, statistically significant inverse associations between tHcy and each cognitive score were obtained within the no-ApoE- $\varepsilon 4$ and the ApoE- $\varepsilon 4$ cohort. For the Basic model, all regression coefficients remained statistically significant for the ApoE- $\varepsilon 4$ cohort, but only the regression coefficient for the Global composite remained significant for the no-ApoE- $\varepsilon 4$ cohort. When the CVD covariate set was introduced, and with further addition of the B-vitamin set, none of the regression coefficients for the no-ApoE- $\varepsilon 4$ cohort were significant. For these models regression coefficients within the ApoE- $\varepsilon 4$ cohort remained significant for the Global composite, MMSE, and Working Memory but were non-significant for Similarities. It should be noted that with adjustment for the Basic 
Table 2

Regression coefficients $(\beta)$, standard errors (S.E.) and significance levels $(p<)$ for $t$-tests of the differences between regression coefficients for the No-Apoe- $\varepsilon 4$ and Apoe- $\varepsilon 4$ groups relating natural log plasma homocysteine to the cognitive measures ${ }^{\mathrm{a}}$

\begin{tabular}{|c|c|c|c|c|c|c|c|c|c|c|c|c|}
\hline \multirow[t]{2}{*}{ Cognitive outcome } & \multicolumn{3}{|c|}{ Unadjusted model } & \multicolumn{3}{|c|}{ Basic model } & \multicolumn{3}{|c|}{ Basic + CVD model } & \multicolumn{3}{|c|}{ Expanded model } \\
\hline & $\begin{array}{l}\text { No-Apoe- } \\
\varepsilon 4\end{array}$ & Apoe- $\varepsilon 4$ & $p<$ & $\begin{array}{l}\text { No-Apoe- } \\
\varepsilon 4\end{array}$ & Apoe- $\varepsilon 4$ & $p<$ & $\begin{array}{l}\text { No-Apoe- } \\
\varepsilon 4\end{array}$ & Apoe- $\varepsilon 4$ & $p<$ & $\begin{array}{l}\text { No-Apoe- } \\
\varepsilon 4\end{array}$ & Apoe- $\varepsilon 4$ & $p<$ \\
\hline \multicolumn{13}{|l|}{ Global } \\
\hline$\beta$ & $-.807^{* * *}$ & $-1.120^{* * *}$ & .05 & $-.213^{*}$ & $-.412^{*}$ & NS & -.029 & $-.491^{* *}$ & .001 & .054 & $-.460^{*}$ & .001 \\
\hline S.E. & .123 & .216 & & .106 & .177 & & .110 & .186 & & .118 & .196 & \\
\hline \multicolumn{13}{|l|}{ MMSE } \\
\hline$\beta$ & $-.471^{* * *}$ & $-.805^{* * *}$ & .05 & -.183 & $-.602^{* *}$ & .01 & -.041 & $-.658^{* *}$ & .001 & .060 & $-.562^{*}$ & .001 \\
\hline S.E. & .124 & .235 & & .127 & .219 & & .129 & .234 & & .139 & .250 & \\
\hline \multicolumn{13}{|l|}{ Similarities } \\
\hline$\beta$ & $-.379^{* *}$ & $-.852^{* * *}$ & .01 & -.202 & $-.493^{*}$ & .05 & -.087 & -.377 & NS & .045 & -.288 & .05 \\
\hline S.E. & .126 & .223 & & .121 & .206 & & .128 & .222 & & .137 & .234 & \\
\hline \multicolumn{13}{|l|}{ Working memory } \\
\hline$\beta$ & $-.376^{* *}$ & $-.922^{* * *}$ & .001 & -.103 & $-.568^{*}$ & .01 & .019 & $-.712^{* *}$ & .001 & .013 & $-.663^{* *}$ & .001 \\
\hline S.E. & .127 & .217 & & .129 & .223 & & .137 & .233 & & .148 & .248 & \\
\hline
\end{tabular}

NS, non-significant.

${ }^{a}$ Values for $t$-tests of differences between $\beta$ s are shown in the online supplement (Table S2, http://www.sciencedirect.com/science/journal/03043940).

* $p<.05$.

** $p<.01$.

*** $p<.001$.

covariate set, Similarities scores were significantly $(p<.05)$ correlated with five of the eleven CVD covariates (BMI, CVD events, diabetes, systolic $\mathrm{BP}$, and alcohol use; $r$ range $=+.11$ to -.20 ), while the other cognitive variables were correlated with no more than three CVD variables ( $r$ range $=+.14$ to -.23 ).

Statistically significant main effects for the Unadjusted and Basic models were observed for the Visual Spatial Memory and Organization $(\beta=-0.785, p<.001 ; \beta=-0.277, p<.01)$ and Scanning and Tracking $(\beta=-1.011, p<.001 ; \beta=-0.300$, $p<.01)$ composites. The Scanning and Tracking main effect persisted with adjustment for the CVD covariate set $(\beta=-0.209$, $p<.05)$, but was attenuated when B-vitamins were added to the model $(\beta=-0.174, p>.05)$. A main effect observed for the Verbal Episodic Memory composite in the Unadjusted model $(\beta=-0.494, p<.001)$ did not persist with adjustment for the Basic covariate set $(\beta=0.078, p>.20)$.

In a final analysis, two CVD sub-models were formed from the CVD covariate set. The first sub-model included the following "primary" CVD variables: CVD events, diabetes mellitus, systolic BP, mild renal dysfunction, total cholesterol, BMI, and hs-CRP. The second, a "life style set", included depressed mood and cigarette, alcohol, and coffee consumption. Findings for both sub-models were the same as those reported above for the CVD model.

To illustrate the magnitude of statistical effects, we compared persons with tHcy values in the highest quintile (Q5, tHcy $>11.8 \mu \mathrm{mol} / \mathrm{l})$ versus the lower four quintiles (Q1-Q4) with regard to two overall measures of cognitive performance, the MMSE and the Global composite, with adjustment for the expanded covariate set. Within the ApoE- $\varepsilon 4$ cohort, persons in tHcy Q5 performed close to 0.30S.D. units below persons in the lower tHcy quintiles on the Global composite $(\beta=-0.294, p<.04)$. This difference between persons in
tHcy Q5 and persons in Q1-Q4 was at 0.40S.D. for the MMSE $(\beta=-0.402, p<.01)$. However, within the no-ApoE- $\varepsilon 4$ cohort, persons in tHcy Q5 did not differ in performance from persons in Q1-Q4 on either the Global composite $(\beta=-0.016, p>.50)$ or the MMSE $(\beta=-0.008, p>.50)$. Differences between these regression coefficients for the ApoE cohorts $(\beta=-0.294$ versus -0.016 and $\beta=-0.402$ versus -0.008 , respectively) were statistically significant for both the Global composite and MMSE $(p s<.01)$.

The magnitude of inverse association between tHcy and cognition was consistently higher for the ApoE- $\varepsilon 4$ cohort than for the no-ApoE- $\varepsilon 4$ cohort for all covariate models. Results within each ApoE cohort varied somewhat depending upon the model employed. For instance, with no adjustment for covariates, significant inverse associations for all cognitive variables were observed for both ApoE cohorts. With adjustment for the basic covariate set, primarily demographic characteristics, only the significant result for the Global composite remained for the no-ApoE- $\varepsilon 4$ cohort. However, results persisted for the ApoE$\varepsilon 4$ cohort for the Global Composite, MMSE, Similarities, and Working Memory.

With further adjustment for the CVD and the B-vitamin covariate sets, the inverse relation between tHcy and Global cognitive performance for the no-ApoE- $\varepsilon 4$ cohort was markedly attenuated and non-significant. In contrast, for the ApoE- $\varepsilon 4$ cohort, further adjustment for the CVD and the expanded covariate set resulted in only modest attenuation of inverse relations between tHcy and cognitive performance for the Global composite, MMSE, and Working Memory. Associations between Similarities (abstract reasoning) scores and tHcy did not persist with adjustment for the CVD covariate set. The greater attenuation of the association between tHcy and Similarities scores, as compared to Global composite, MMSE, and Working Memory 
scores, may reflect the fact that Similarities was correlated significantly with a greater number of the CVD variables than were the other cognitive scores.

Although the interaction between ApoE genotype and tHcy has been studied at the cellular level to explain their effect on atheroma formation $[21,47]$ and neuronal cell cycle dysregulation in the brain [29], only two studies report the modification of tHcy relations with cognitive performance by the ApoE genotype. Dufouil et al. [7] did not find that ApoE genotype modified associations of tHcy with cognitive decline. Schafer et al. [38] found that the cross-sectional association of tHcy with performance on the Rey Auditory Verbal Learning Test was stronger in individuals homozygous for the ApoE- $\varepsilon 4$ allele than those carrying only one $\varepsilon 4$ allele or no $\varepsilon 4$ alleles. Our study differed from this study in that we employed fasting tHcy values, adjusted for vitamin concentrations as well as CVD factors and combined cohorts carrying either one or two ApoE- $\varepsilon 4$ alleles for our major analyses given statistical power considerations.

Because of the evidence that higher tHcy might be neurotoxic $[14,20,24,32]$, it is instructive to consider potential mechanisms involved in the relation between the ApoE- $\varepsilon 4$ allele and cognitive performance, particularly those mechanisms pertaining to neuronal damage and repair. It has been argued that atrophy of the hippocampus and loss of its connectivity play a role in ApoE- $\varepsilon 4$-related deficits in test performance depending on memory [43]. Also, there is evidence that cholinergic transmitter decrements in those persons with an ApoE- $\varepsilon 4$ genotype are seen in temporo-parietal brain areas involving integrative, psychomotor and visual abilities [31]. Small et al. [42] argue that the interplay between several mechanisms may better explain the broad range of deficits seen in ApoE- $\varepsilon 4$ carriers. ApoE- $\varepsilon 4$ is related to cardiovascular disease $[16,42,44]$ which, in turn, is related to cognitive deficit [10]. ApoE- $\varepsilon 4$ genotype has also been implicated in the altered metabolism of beta-amyloid and the formation of neurofibrillary tangles [44]. Additionally, ApoE$\varepsilon 4$ genotype is related to impairments in neuronal maintenance and repair [18]. Though speculative, the interplay between tHcy and ApoE- $\varepsilon 4$ genotype may be more than a summation of different deleterious effects, i.e. ApoE- $\varepsilon 4$ genotype is associated with neuronal susceptibility to insult while higher tHcy is associated with greater neuronal death.

Limitations of this study include: (1) the cross-sectional design; and (2) the relatively high levels of education of our participants which may serve to attenuate the magnitude of associations between tHcy and cognitive performance for both ApoE cohorts.

In an era focused on pre-clinical disease and prevention, the magnitude of the impact of plasma tHcy and ApoE genotype on cognitive performance is crucial. With adjustment for the Expanded model (Basic + CVD + B-vitamin covariates), we found that persons with high, as versus low, plasma tHcy in the presence of an ApoE- $\varepsilon 4$ allele performed 0.30S.D. and 0.40S.D. lower on the Global composite and the MMSE, respectively. Deficits of this magnitude are of considerable importance at the population level and constitute a risk factor for dementia [8].

Our results are consistent with a model in which the ApoE$\varepsilon 4$ allele is seen as conferring vulnerability to other risk factors and pathophysiological phenomena related to lower cognitive performance [4]. Additional studies are needed in order to understand the mechanism explaining the interplay between plasma tHcy and ApoE genotype with regard to cognitive performance in a non-demented sample.

\section{Acknowledgments}

This study was supported by Research Grant HL67358 from the National Heart, Lung, and Blood Institute, National Institutes of Health (USA), Research Grant AG03055 from the National Institute on Aging, National Institutes of Health (USA), the Alzheimer's Research Trust (UK), and the Charles Wolfson Charitable Trust (UK).

\section{Appendix A. Supplementary data}

Supplementary data associated with this article can be found, in the online version, at doi:10.1016/j.neulet.2007.10.021.

\section{References}

[1] P. Bretsky, J.M. Guralnik, L. Launer, M. Albert, T.E. Seeman, The role of APOE-epsilon4 in longitudinal cognitive decline: MacArthur studies of successful aging, Neurology 60 (2003) 1077-1081.

[2] M.M. Budge, C. de Jager, E. Hogervorst, A.D. Smith, Total plasma homocysteine, age, systolic blood pressure, and cognitive performance in older people, J. Am. Geriatr. Soc. 50 (2002) 2014-2018.

[3] D. Bunce, M. Kivipelto, A. Wahlin, E. Apolipoprotein, B vitamins, and cognitive function in older adults, J. Gerontol. B Psychol. Sci. Soc. Sci. 60 (2005) P41-P48.

[4] D. Bunce, M. Kivipelto, A. Wahlin, Utilization of cognitive support in episodic free recall as a function of apolipoprotein E and vitamin B12 or folate among adults aged 75 years and older, Neuropsychology 18 (2004) 362-370.

[5] R. Clarke, A.D. Smith, K.A. Jobst, H. Refsum, L. Sutton, P.M. Ueland, Folate, vitamin B12, and serum total homocysteine levels in confirmed Alzheimer disease, Arch. Neurol. 55 (1998) 1449-1455.

[6] D.W. Cockcroft, M.H. Gault, Prediction of creatinine clearance from serum creatinine, Nephron 16 (1976) 31-41.

[7] C. Dufouil, A. Alperovitch, V. Ducros, C. Tzourio, Homocysteine, white matter hyperintensities, and cognition in healthy elderly people, Ann. Neurol. 53 (2003) 214-221.

[8] M.F. Elias, A. Beiser, P.A. Wolf, R. Au, R.F. White, R.B. D'Agostino, The preclinical phase of Alzheimer disease: a 22-year prospective study of the Framingham Cohort, Arch. Neurol. 57 (2000) 808-813.

[9] P.K. Elias, M.F. Elias, R.B. D’Agostino, L.M. Sullivan, P.A. Wolf, Serum cholesterol and cognitive performance in the Framingham Heart Study, Psychosom. Med. 67 (2005) 24-30.

[10] M.F. Elias, P.K. Elias, M.A. Robbins, P.A. Wolf, R.B. D'Agostino, Cardiovascular risk factors and cognitive functioning: an epidemiological perspective, in: S. Waldstein, M.F. Elias (Eds.), Neuropsychology of Cardiovascular Disease, Lawrence Erlbaum Associates, Inc., Hillsdale, NJ, 2001, pp. 83-105.

[11] M.F. Elias, M.A. Robbins, M.M. Budge, P.K. Elias, S.L. Brennan, C. Johnston, Z. Nagy, C.J. Bates, Homocysteine, folate, and vitamins B6 and B12 blood levels in relation to cognitive performance: the Maine-Syracuse study, Psychosom. Med. 68 (2006) 547-554.

[12] M.F. Elias, L.M. Sullivan, R.B. D'Agostino, P.K. Elias, P.F. Jacques, J. Selhub, S. Seshadri, R. Au, A. Beiser, P.A. Wolf, Homocysteine and cognitive performance in the Framingham offspring study: age is important, Am. J. Epidemiol. 162 (2005) 644-653.

[13] L.A. Farrer, L.A. Cupples, J.L. Haines, B. Hyman, W.A. Kukull, R. Mayeux, R.H. Myers, M.A. Pericak-Vance, N. Risch, C.M. van Duijn, 
Effects of age, sex, and ethnicity on the association between apolipoprotein E genotype and Alzheimer disease. A meta-analysis. APOE and Alzheimer Disease Meta Analysis Consortium, J. Am. Med. Assoc. 278 (1997) 1349-1356.

[14] E.M. Fykse, E.G. Iversen, F. Fonnum, Inhibition of L-glutamate uptake into synaptic vesicles, Neurosci. Lett. 135 (1992) 125-128.

[15] M.N. Haan, L. Shemanski, W.J. Jagust, T.A. Manolio, L. Kuller, The role of APOE epsilon4 in modulating effects of other risk factors for cognitive decline in elderly persons, J. Am. Med. Assoc. 282 (1999) 4046.

[16] G.J. Hankey, J.W. Eikelboom, Homocysteine and vascular disease, Lancet 354 (1999) 407-413.

[17] J.E. Hixson, D.T. Vernier, Restriction isotyping of human apolipoprotein E by gene amplification and cleavage with HhaI, J. Lipid. Res. 31 (1990) $545-548$.

[18] K. Horsburgh, M.O. McCarron, F. White, J.A. Nicoll, The role of apolipoprotein E in Alzheimer's disease, acute brain injury and cerebrovascular disease: evidence of common mechanisms and utility of animal models, Neurobiol. Aging 21 (2000) 245-255.

[19] D.M. Kado, A.S. Karlamangla, M.H. Huang, A. Troen, J.W. Rowe, J. Selhub, T.E. Seeman, Homocysteine versus the vitamins folate, B6, and B12 as predictors of cognitive function and decline in older high-functioning adults: MacArthur studies of successful aging, Am. J. Med. 118 (2005) 161-167.

[20] Kruman II, C. Culmsee, S.L. Chan, Y. Kruman, Z. Guo, L. Penix, M.P. Mattson, Homocysteine elicits a DNA damage response in neurons that promotes apoptosis and hypersensitivity to excitotoxicity, J. Neurosci. 20 (2000) 6920-6926.

[21] S.R. Lentz, Mechanisms of homocysteine-induced atherothrombosis, J. Thromb. Haemost. 3 (2005) 1646-1654.

[22] G. Leoncini, F. Viazzi, D. Parodi, S. Vettoretti, E. Ratto, M. Ravera, C. Tomolillo, M. Del Sette, G.P. Bezante, G. Deferrari, R. Pontremoli, Mild renal dysfunction and subclinical cardiovascular damage in primary hypertension, Hypertension 42 (2003) 14-18.

[23] M.D. Lezak, D.B. Howieson, D.W. Loring, Neuropsychological Assessment, Oxford University Press, New York, 2004, xiv, 1016 pp.

[24] S.A. Lipton, W.K. Kim, Y.B. Choi, S. Kumar, D.M. D'Emilia, P.V. Rayudu, D.R. Arnelle, J.S. Stamler, Neurotoxicity associated with dual actions of homocysteine at the $N$-methyl- $D$-aspartate receptor, Proc. Natl. Acad. Sci. U.S.A. 94 (1997) 5923-5928.

[25] A. McCaddon, G. Davies, P. Hudson, S. Tandy, H. Cattell, Total serum homocysteine in senile dementia of Alzheimer type, Int. J. Geriatr. Psychiatry 13 (1998) 235-239.

[26] A. McCaddon, P. Hudson, G. Davies, A. Hughes, J.H. Williams, C. Wilkinson, Homocysteine and cognitive decline in healthy elderly, Dement. Geriatr. Cogn. Disord 12 (2001) 309-313.

[27] G. McKhann, D. Drachman, M. Folstein, R. Katzman, D. Price, E.M. Stadlan, Clinical diagnosis of Alzheimer's disease: report of the NINCDSADRDA Work Group under the auspices of Department of Health and Human Services Task Force on Alzheimer's Disease, Neurology 34 (1984) 939-944.

[28] J.W. Miller, R. Green, M.I. Ramos, L.H. Allen, D.M. Mungas, W.J. Jagust, M.N. Haan, Homocysteine and cognitive function in the Sacramento Area Latino Study on aging, Am. J. Clin. Nutr. 78 (2003) 441-447.

[29] Z. Nagy, Cell cycle-related protein expression in Alzheimer's disease and vascular disease, Int. Psychogeriatr. 15 (Suppl. 1) (2003) 77-79.
[30] B.P. Nathan, S. Bellosta, D.A. Sanan, K.H. Weisgraber, R.W. Mahley, R.E. Pitas, Differential effects of apolipoproteins E3 and E4 on neuronal growth in vitro, Science 264 (1994) 850-852.

[31] R. Parasuraman, P.M. Greenwood, T. Sunderland, The apolipoprotein E gene, attention, and brain function, Neuropsychology 16 (2002) 254-274.

[32] R.B. Parsons, R.H. Waring, D.B. Ramsden, A.C. Williams, In vitro effect of the cysteine metabolites homocysteic acid, homocysteine and cysteic acid upon human neuronal cell lines, Neurotoxicology 19 (1998) 599-603.

[33] N.D. Prins, T. Den Heijer, A. Hofman, P.J. Koudstaal, J. Jolles, R. Clarke, M.M. Breteler, Homocysteine and cognitive function in the elderly: the Rotterdam Scan Study, Neurology 59 (2002) 1375-1380.

[34] L.S. Radloff, The CES-D scale: a self-report depression scale for research in the general population, Appl. Psychol. Meas. 1 (1977) 385-401.

[35] H. Refsum, P.M. Ueland, O. Nygard, S.E. Vollset, Homocysteine and cardiovascular disease, Annu. Rev. Med. 49 (1998) 31-62.

[36] B. Regland, K. Blennow, T. Germgard, A.C. Koch-Schmidt, C.G. Gottfries, The role of the polymorphic genes apolipoprotein $\mathrm{E}$ and methylenetetrahydrofolate reductase in the development of dementia of the Alzheimer type, Dement. Geriatr. Cogn. Disord 10 (1999) 245-251.

[37] K.M. Riggs, A. Spiro 3rd, K. Tucker, D. Rush, Relations of vitamin B12 , vitamin B-6, folate, and homocysteine to cognitive performance in the Normative Aging Study, Am. J. Clin. Nutr. 63 (1996) 306-314.

[38] J.H. Schafer, T.A. Glass, K.I. Bolla, M. Mintz, A.E. Jedlicka, B.S. Schwartz, Homocysteine and cognitive function in a population-based study of older adults, J. Am. Geriatr. Soc. 53 (2005) 381-388.

[39] J. Selhub, L.C. Bagley, J. Miller, I.H. Rosenberg, B vitamins, homocysteine, and neurocognitive function in the elderly, Am. J. Clin. Nutr. 71 (2000) 614S-620S.

[40] S. Seshadri, A. Beiser, J. Selhub, P.F. Jacques, I.H. Rosenberg, R.B. D'Agostino, P.W. Wilson, P.A. Wolf, Plasma homocysteine as a risk factor for dementia and Alzheimer's disease, N. Engl. J. Med. 346 (2002) 476-483.

[41] M.T. Shipchandler, E.G. Moore, Rapid, fully automated measurement of plasma homocyst(e)ine with the Abbott IMx analyzer, Clin. Chem. 41 (1995) 991-994.

[42] B.J. Small, A.B. Graves, C.L. McEvoy, F.C. Crawford, M. Mullan, J.A. Mortimer, Is APOE-epsilon4 a risk factor for cognitive impairment in normal aging? Neurology 54 (2000) 2082-2088.

[43] B.J. Small, C.B. Rosnick, L. Fratiglioni, L. Backman, Apolipoprotein E and cognitive performance: a meta-analysis, Psychol. Aging 19 (2004) 592-600.

[44] J.D. Smith, Apolipoproteins and aging: emerging mechanisms, Ageing Res. Rev. 1 (2002) 345-365.

[45] C.E. Teunissen, A.H. Blom, M.P. Van Boxtel, H. Bosma, C. de Bruijn, J. Jolles, B.A. Wauters, H.W. Steinbusch, J. de Vente, Homocysteine: a marker for cognitive performance? A longitudinal follow-up study, J. Nutr. Health Aging 7 (2003) 153-159.

[46] K.L. Tucker, N. Qiao, T. Scott, I. Rosenberg, A. Spiro 3rd, High homocysteine and low B vitamins predict cognitive decline in aging men: the Veterans Affairs Normative Aging Study, Am. J. Clin. Nutr. 82 (2005) 627-635.

[47] J. Zhou, G.H. Werstuck, S. Lhotak, A.B. de Koning, S.K. Sood, G.S. Hossain, J. Moller, M. Ritskes-Hoitinga, E. Falk, S. Dayal, S.R. Lentz, R.C. Austin, Association of multiple cellular stress pathways with accelerated atherosclerosis in hyperhomocysteinemic apolipoprotein E-deficient mice, Circulation 110 (2004) 207-213. 